\title{
Interprofessional training on resilience-building for children who experience trauma: Stakeholders' views from six low- and middle-income countries
}

\begin{abstract}
Children exposed to multiple adversities are at high risk of developing complex mental health and related problems, which are more likely to be met through integrated interprofessional working. Combining the expertise of different practitioners for interprofessional care is especially pertinent in low- and middle-income countries (LMIC) in the absence of specialist resources. The aim of this study was to work with practitioners who deliver care to vulnerable children in six LMIC (Turkey, Pakistan, Indonesia, Kenya, Rwanda and Brazil) to understand their perspectives on the content of an interprofessional training programme in building resilience for these children. Seventeen participants from different professional backgrounds, who were in contact with vulnerable children were interviewed. A thematic analytic framework was used. Four themes were identified, which were the benefits of a tiered approach to training, challenges and limitations, perceived impact, and recommendations for future training. The findings indicate the importance of co-ordinated policy, service and training development in an interprofessional context to maximize resources; the need for cultural adaptation of skilled-based training and interventions; and the usefulness of new technologies to enhance accessibility and reduce costs in LMIC.
\end{abstract}

Key terms: Interprofessional education, child mental health, trauma, low/middle income countries, qualitative methods, interviews

\section{Introduction}

The rationale and importance of working with vulnerable children

Children with mental health problems often have inter-related social, educational and physical health care needs (Green, Mc Ginnity, Meltzer, Ford, \& Goodman, 2005). These are particularly pronounced among vulnerable groups of children and young people who experience multiple risk factors for the development of mental health problems; for example children in public care, refugee, homeless, or living in disadvantage (O'Reilly, Taylor, \& Vostanis, 2009). Despite the differences between these groups of children, research has 
shown that that their mental health issues arise similarly but they follow different trajectories (Vostanis, 2010). Professional agencies and their practitioners often work in silo rather than through interprofessional collaboration, defined as "interprofessional work which involves different health and social care professions who regularly come together to solve problems and provide services" (Reeves, Lewin, Espin, \& Zwarenstein, 2010, p. xiii). This silo working offers no consensus of patient-centred shared goals, and results in fragmentation, duplicate referrals and increased costs (Vostanis, Meltzer, Goodman, \& Ford, 2003). This applies to other vulnerable population groups, and underpins the reason behind recent growth towards integrated care involving pooled budgets in accountable care systems (Charles, 2017).

This evidence-base has influenced child mental health policy, service development and interventions in acknowledging the importance of interprofessional collaboration, to maximize resources and provide more integrated service provision to children and families (NHS England, 2015). For example, He, Lim, Lecklinter, Olson, and Traube (2015) found that such collaboration led to better recognition of child mental health problems, thus more cost-effective referrals. As the majority of common child mental health problems will not require input from specialist services, equipping frontline practitioners both with competencies related to their role and with an interprofessional context has thus become priority for child mental health care systems (NHS England, 2014).

\section{Interprofessional training to support practitioners working with vulnerable children}

The importance of interprofessional training for professionals working with vulnerable children is now widely understood in high-income countries. For example, in the UK such programmes were first set up in response to inter-agency policies and commissioning 
(Sebuliba, \& Vostanis, 2001). These were positively received by health, education and social care agencies staff in enhancing knowledge and skills, whilst improving joint working (Madge, Foreman, \& Baksh, 2008). In a systematic review that included 33 studies, Cooper, Evans, and Pubis (2016) identified joint training as a key facilitator of interprofessional collaboration across several countries. One challenge for these educational initiatives is their direct dependence on commissioning that adopts an interprofessional philosophy, which is more susceptible to service cost reduction. Consequently, many such policy-led initiatives have been relatively short-lived, thus not sustainable. This has been a longstanding issue for the development of interprofessional competence using interprofessional education (Gilbert, 2005; WHO, 2010; IOM, 2015). Other barriers have been the lack of common language, joint outcomes and evidence-base (Worrall-Davies, \& Cottrell, 2009).

We could postulate that interprofessional training for practitioners working in other global areas, where services are often even more delineated, may potentially have an even higher impact in the absence of well-developed specialist services, i.e. in low- and middle-income countries (LMIC). Here, primary health care, education, welfare and non-governmental organizations (NGOs) are the key mental health providers (Kieling et al., 2011; Patel, \& Rahman, 2015). Particularly in regions of conflict and extreme deprivation, children's high rates of unmet mental health needs are well-documented (Fleitlich-Bilyk, \& Goodman, 2004; Hussein, Vostanis, \& Bankart, 2012). Resource gaps are compounded by stigma of mental illness and lack of cultural adaptation of interventions (Amuyunzu-Nyamongo, 2013; Abera, Robbins, \& Tesfaye, 2015).

A number of models have been reported in recent years, although not in an interprofessional context, usually through mental health interventions within schools or primary health care 
(Fazel, Patel, Thomas, \& Tol, 2014; Lund, Tomlinson, \& Patel, 2016). A two-day training workshop for 114 teachers from five schools in Pakistan was associated with improved awareness, knowledge and formulation of strategies (Hussein, \& Vostanis, 2013). Parenting interventions have been contextualised to culture and high risk situations, with promising outcomes on feasibility, parent-child interaction and knowledge of child development (Knerr, Gardner, \& Cluver, 2013), although families do not usually participate in this process (Losa, \& Effat, 2017). There is, however, growing awareness of the need for community leads and representatives being actively involved in interprofessional networks (Draper, Hewitt, \& Rifkin, 2010), and training for lay workers (Patel, Chowdhary, Rahman, \& Vardeli, 2011) in enhancing children's and young's people resilience in both alleviating and preventing mental health problems.

Building resilience: The training agenda for practitioners working with vulnerable children It is now beginning to be recognised that to tackle vulnerable children's resilience, interprofessional education for practitioners involved in supporting these children might be necessary (Eruyar, Huemer, \& Vostanis, 2017). A key challenge in responding to policy calls to enhance resilience skills in children and young people is providing an interprofessional care context. In addition, across the literature there is considerable disparity in defining what is meant by psychological resilience (Maltby, Day, \& Hall, 2015). Current definitions of resilience are often either ubiquitous, for example any variable is considered as a resilient factor so long as it alleviates the impact of a negative event (for example, buffering hypothesis: Johnson, Wood, Gooding, Taylor, \& Tarrier, 2011); or, ambiguous, with recent reviews suggesting over 25 different ways to assess resilience in terms of hardiness, coping, optimism, perseverance, impulse control and self-efficacy (Windle, Bennett, \& Noyes, 2011; Pangallo, Zibarras, \& Lewis, 2015). In general, vulnerable children need interprofessional 
collaboration using co-ordinated care pathways, where the understandings of how to ensure resilience for recovery are agreed between all practitioners.

Currently the clinical approaches to childhood resilience vary between practitioners who employ up to eight different conceptual approaches, including risk, inoculation effects, mental attributes, biological features and the effects of social relationships (Rutter, 2013). Therefore, when it comes to responding to build resilience among children, the ubiquity and ambiguity that exists in identifying what resilience is, does not allow for the development of clear programmes for resilience-building for interprofessional collaboration. As such there is a need to consider shared understandings between the different practitioners, that is, given the lack of a clear definition of resilience, what primary factors do professionals think might be resilience factors that alleviate the impact of negative events.

\section{Background}

The countries and settings were selected as active partners in an ongoing programme to develop a psychosocial model for vulnerable children in LMIC through interprofessional collaborative work (www.wacit.org). This programme was designed to maximize impact through new partnerships with academic centres and non-governmental organizations (NGOs) operating in disaster zones, training programmes and materials, and capacitybuilding. This includes inter-linked projects funded through different agreements. Invited participants included all professional and volunteer caregivers in a selected area in contact with a vulnerable group.

A strategic approach to the selection of international partners was taken, to ensure inclusion of countries and communities within them, from across the LMIC income spectrum 
according to OECD criteria (OECD, 2016). This ensured a range of trauma levels associated with poverty and other collective characteristics, i.e. upper middle (Turkey, Brazil), lower middle (Pakistan, Indonesia), and other low income countries (Kenya, Rwanda). The respective vulnerable groups, were: street and refugee children (Turkey), living in slum areas and orphanages (Pakistan), favelas (Brazil), community care homes (Rwanda), and living in slums following ethnic violence / internal displacement (Kenya).

A lead organization was identified for each centre and vulnerable group. At the next stage, this organization invited all agencies in contact with children within this area. These agencies were subsequently asked to nominate key professionals, volunteers and community leads to attend a two-day workshop facilitated by the first author (in reality this varied between one and three days, depending on staff capacity and availability). Such engagement with core stakeholders within the nominated country is essential for any sustainable intervention designed to improve the mental wellbeing of vulnerable children.

This study centred on the outcomes of the interprofessional workshops with partner organizations and their representative practitioners, which aimed to develop a resiliencebuffering hypothesis. The workshops adapted an interprofessional stance designed, so that participants interacted to learn 'with, from and about one another' in order to share their common approaches to resilience building (WHO, 2010 p. 6); although it is acknowledged that this did not primarily focus on interprofessional learning, because of the exploratory nature of such an endeavour in LMIC. Approaches from previous interprofessional training with caregivers and practitioners of vulnerable children were utilized (Allen, \& Vostanis, 2005). Content focussed on the following objectives: awareness of mental health and psychosocial needs; understanding of how trauma impacts on children's mental health; key 
aspects of child development; building resilience in relation to one's role; recognition of common child mental health problems and related family, social care and educational needs; and formulation of interprofessional goals along four domains of the ecological systems framework, i.e. child, family or caregiver, school, and community. The workshops involved small-group and case-based discussion tailored to participants' experience. These took place between April 2015 and March 2016.

\section{Methods}

The study utilized an exploratory case study design (Yin, 2012), because of the nature of the research goals, and the limited evidence-base from developing countries in this area. A broadly social constructionist theoretical framework underpinned the approach, and thus the participant-centred approach to data collection reflects this, and the analytic process provides the constructed accounts of those directly experiencing the training (Burr, 2003).

\section{Participants}

Each interprofessional workshop was attended by 20-80 participants. From each country the co-ordinator identified one stakeholder from each group, according to two criteria, i.e. involvement in the programme from the outset, and the longest experience within their group: policy, practice, university or caregiving. Of the 18 stakeholders invited, 17 agreed to participate in the study (two from Brazil and three from each of the remaining countries). These included one NGO chief executive and two NGO managers, one NGO project coordinator, one social worker, two psychiatrists, four psychologists (two academic), three educationalists, one probation officer, one health volunteer, and one children's home caregiver. None of the participants were members of an interprofessional team, but they 
rather attended training in an interprofessional context. Participants were interviewed between three and six months after attending the training.

\section{Data collection}

Semi-structured interviews provided the mechanism to explore participant perspectives. This approach to data collection was favoured, as it allows flexibility in capturing participants' views on their knowledge of support networks in their area, perceived benefits and challenges, value of learning with others, and understanding about other professional perspectives in meeting vulnerable children's complex psychosocial needs.

Semi-structured interviewing is a popular and useful strategy for gaining important insight from participant perspectives (Roulston, 2010). These were audio-recorded and conducted via Skype, telephone or other media. All interviews were conducted in English language, although the range of participants' verbal English varied. Due to language difficulties, some questions required rephrasing, and some answers initially lacked coherence or were fragmented. Therefore, the representation of these answers as direct quotations is also fragmented in places. Aligning with the qualitative framework for a thematic design, recruitment continued until saturation was achieved (O’Reilly, \& Parker, 2013).

\section{Data analysis}

Data were analysed using thematic analysis, allowing meaning to be drawn through a datadriven strategy to identify core patterns (Braun \& Clarke, 2006). A coding framework was developed by utilizing a tiered approach to coding, first, second and third order levels (Boyatzis, 1998). In practice, the 'pawing' technique for coding was utilized, that is, systematically trawling through the entire data corpus multiple times, ensuring that the 
second order coding frames collapsed into broader themes of relevance (Ryan, \& Bernard, 2003). This was facilitated by an 'eyeballing' technique, which involves repeatedly looking through the data by scanning through to identify codes of interest, engaging in repeated sorting by multiple coders to ensure consistency (Bernard, 2000). Data were transcribed verbatim and were independently coded by several members of the team to improve interrater reliability. These multiple coding frames were then mapped and integrated prior to analysis, and agreements on the final third order codes reached. Thus, all second order categories were examined systematically by key research team members to identify core themes that addressed the aims of the research. This process is represented visually in Figure 1. The themes and sub-themes which emerged from the analytical process are presented in Table 1.

\section{INSERT FIGURE $1 \&$ TABLE 1 ABOUT HERE}

\section{Ethical considerations}

Research ethics approval was granted by the University of Leicester Psychology Research Ethics Committee. The six country co-ordinators were approached by independent researchers who had not previously met the participants. The aims of the study and consent procedures were explained verbally and in writing.

\section{Results}

The training model utilized a biopsychosocial layered approach to upskilling a range of professionals, by putting in place a framework around the child. In providing training for these professionals and key stakeholders, analysis identified four core areas that need to be addressed, if these objectives are to be emulated by others in the future and delivered 'on the 
ground': 1) benefits of a tiered approach addressing multiple areas of need; 2) recognizing the challenges and limitations that might hinder delivery; 3) areas where impact can be achieved; and 4) suggestions for future training.

\section{Benefits of a tiered approach to training}

A central finding from the evaluation of the (anonymized) training programme was that professionals welcomed the opportunity and encouragement to share knowledge and ideas with each other, an undertaking which had not been usually undertaken before:

...the keynote speaker has different perspective, and also participants come from different areas and different occupation. There were teachers, they were also NGOs, government... (Education and Health, Indonesia)

Evident from the participants was that the opportunity for different professionals and disciplinary representatives, including 'NGOs' and 'government' was of specific benefit to working with vulnerable children. By sharing ideas with each other, professionals and stakeholders can promote the delivery of knowledge and practice, therefore their learning context and experience are important. The nature of any training delivered in these countries needs to account for the role that childhood trauma plays in contributing to mental health problems. In so doing, both the theoretical aspects of vulnerability and the evidence-based strategies that professionals can implement, need to be addressed. Participants welcomed the theoretical foundational knowledge provided in the programme, but also the practical ideas for helping them daily to deal with behaviours expressed by the children:

After attending this workshop, now we had theoretical background of trauma, and we know how it affects children. (Education and Health, Turkey)

It was great that (facilitator) built up the theoretical part and the other guys taught practical things, and the two went really well together. (Education and Health, Turkey) 
People came to learn that simple predisposing factors are important to note when making treatment plans, and that can be helpful in understanding the dynamics of trauma and how functional treatment works. (Health, Pakistan)

In addressing children's mental health needs, it is important to have a clear understanding of the theoretical basis of mental health conditions, and how these are inter-linked with traumatic experiences. Practitioners then need to appreciate how interventions are grounded in both theory and evidence. Such integration of theoretical knowledge "now we had theoretical background of trauma" and practical work "taught practical things" (Education and Health, Turkey) appeared to be appreciated by participants. This is especially important, as vulnerable children under their care had complex needs:

...tell (facilitator) the very difficult people we have, their behaviour and he explain to us one by one what we can do. (Welfare, Rwanda)

The way in which vulnerable children's complex needs are addressed requires a multidimensional approach, and thus the implication from the participants is that any training programme should account for the potentially limited knowledge of professionals, and should provide information at both a theoretical and practical level. Importantly, this transcends the professional domain to some extent, as participants discussed how simply allowing a forum for carers to come together and share experiences was positively received:

[It] was wonderful to see these carers who had never really shown any interest at the orphanage, all chatting together, exchanging stories of each of the people they care for. (Welfare, Rwanda)

No one has ever listened or helped or cared, so it was wonderful to see them so involved and all scrabbling over themselves to give their opinion... (Welfare, Rwanda)

\section{Challenges and limitations}


Participants provided useful insight, particularly in sharing and implementing new knowledge and skills. An obvious difficulty for training involving external facilitators can be language. In these cases, some of the training to professionals was delivered in English, and some in their native language through the use of interpreters or co-facilitators acting as interpreters for example, Bahasa in Indonesia, Swahili in Kenya, Portuguese in Brazil, and Urdu in Pakistan:

In UK, there are people from all over the world. You have phrases which can be difficult. In Brazil...almost everyone speaks Portuguese and only a few can understand English well... (Health, Brazil)

Because the training conducted in English, especially the session with (facilitator), most of the participants, they didn't really understand with English language, they didn't really catch the message from (facilitator), but because the second session was conducted in Indonesian language, they mostly can understand. (Education and Health, Indonesia)

Issues of resources are especially problematic for LMIC and, even in circumstances whereby training could be provided without cost to the participants, resource issues were still a fundamental challenge. For example, participants reported that release from their work, space and other venue issues constrained access to the training.

...like I was telling you, the charity was small, the number of people we have been inviting is because we cannot manage more capacity than that. (Welfare, Kenya)

“...someone who can stay here for a long time for class.” (Welfare, Rwanda)

Release from work seemed to be problematic for many participants, as they reported that they found it difficult to be given time for the training "who can stay here for a long time for class" (Welfare, Rwanda) and having the "capacity" (Welfare Kenya) to release people. Despite this challenge, however, they did hope that the training could be extended, as one 
participant noted, "I just wish we could have had a few more days" (Welfare, Rwanda). For another:

...because of so many questions they asked, [facilitator] had to answer them. He had not had much time for techniques. (Welfare and Health, Turkey)

The suggestion from participants was that the training needed to continue for more days than originally scheduled, as there was insufficient time to cover all areas of interest. As this was a foundation training programme designed to cover essential areas of mental health and trauma, the responses suggest that a more in-depth, skilled-based and lengthy training schedule should be considered next. Indeed, participants argued that they would welcome more training should it become available to them. As one noted, "we didn't get enough training to help the child" (Welfare, Pakistan). Another mentioned:

"It's not enough, because...to give service to the children, we need more training, I think." (Welfare, Indonesia)

It was evident from these responses that participants believed that the training delivered was not enough to help them in their daily and ongoing professional activities. They clearly wanted further skills development in specific strategies: "we need more training; we didn't' get enough training" (Welfare, Indonesia); which suggests that those related to the field of mental health valued the opportunity to learn about its concepts and applications, and would be willing to invest more time and effort into further programmes.

\section{Perceived impact}

The enthusiasm for further training around the biopsychosocial needs of children in trauma was emphasized in relation to the impact that participants believed the training programme had on their skills and on the children they worked with. It was reported that the training 
received promoted their knowledge, awareness and skills, which consequently allowed them to work more effectively with vulnerable children:

I think about awareness, awareness is the short-term impact. Awareness about trauma. (Education and Health, Indonesia)

...there were others who never realized that it was very important to understand how to deal with these children. There were some who didn't understand what is the impact of trauma on these children. Now their eyes have opened up, and people started understanding that it is something that is very, very important. (Welfare, Kenya)

They now understand what any child who is emotionally disturbed, or has suffered any kind of emotional trauma, what they are thinking or what types of challenges or risk patterns that they will have faced. (Welfare, Pakistan)

Participants reported the positive effects of learning about trauma and "have their eyes opened up" (Welfare, Kenya) to the realities faced by them. Therefore, increasing knowledge and understanding of how adversities and stigma are inter-connected among vulnerable groups could be important in this context. In addition, this may have provided staff with a sense of empowerment and hope, as they began to realize that these were difficulties faced by many others across the globe:

When he talked about his experiences on the other projects around the world, the participants felt hope, they were comforted by the fact that they were not alone, that other people worldwide were going through the same. They felt empowerment. (Health, Brazil)

The way I saw it, it was like a wake-up call. Number one, people informed they became enlightened, they understood that actually they need to do something... (Welfare, Kenya)

[It] gave them a lot of confidence and made them feel that, yes, they could, and that the therapy works. (Health, Pakistan)

An important perceived impact of the training provided was that participants felt more confident to manage in their role, but also that they were not an isolated country dealing with such issues. As the training provided simple information that demonstrated some of the 
global challenges faced in the field of mental health, this helped them feel "comforted"

(Health, Brazil). Furthermore, attending this kind of training gave them sufficient confidence in many of the practices they were already using in their roles of providing support for children and families. Doing so in an interprofessional context can be even more reassuring:

I think the participants found that they were already doing most of the things that were being talked about, and they thought it was reassuring that they now had theoretical work supporting what they already do. (Health, Brazil)

...it was amazing to see them all interacting with each other, and [facilitator] was able to stand back and say they already know. (Welfare, Rwanda)

Similar views were expressed in relation to existing individual competencies. Participants reported that engaging with other professionals in their area, especially through small group exercises, provided a mechanism for recognizing that some of the work they were doing was adequately meeting children's needs, “reassuring that they now had theoretical work supporting what they already do" (Health, Brazil). Indeed, participants found it "amazing" to see that professionals grew in confidence, as the training supported what they "already know" (Welfare, Rwanda). Furthermore, they could recognize the importance of good communication skills and rapport-building, as a child-centred approach to mental health care was promoted throughout the training:

...this make me more close to them, so I can make a good relation and they more trust me, and it is good to continue this relation. (Welfare, Indonesia)

The children are more open, they can talk about their problems and what they are feeling more...I think they can be more open, so I know what they want, something like that. (Welfare, Indonesia)

Recognition that developing therapeutic relationships with clients and interprofessional communication skills are essential in mental health care was outlined. Participants noted that their improved skills and confidence resulted in building stronger relationships with the children, and promoted trust and openness. Thus, a perceived impact of the training was their 
encouragement of children to be "more open" (Welfare, Indonesia), which is important for positive therapeutic outcomes:

I have a new perspective, I have a different point of view, so I can...more easy to face the children with trauma when they have problems, so it's more...easy to handle them. (Welfare, Indonesia)

They have the whole school and they are talking to them, teaching them, and to make them understand how they need to look after themselves in such areas and situations...it has taken information from the training into the community. (Welfare, Kenya)

Notably, participants recognized that the way the training was designed meant that the key messages and techniques were translated into practice for other professionals that they worked with. For example, the training provided a basis for the whole school to be involved in promoting mental wellbeing, and in teaching professionals as well as children in how to "look after themselves", which in turn allowed information to be passed on "into the community" (Welfare, Kenya).

\section{Recommendations for future training}

Participants argued that, while the theoretical understanding of the impact of trauma on children was important (as noted earlier), the most relevant and useful aspects of any training programme were the practical strategies:

...we need to make it so people are not just being talked at, them sitting in a room being told theoretical things. Need to make it practical, so it's not passive... (Health, Brazil)

My requirement...is conducting another workshop with professionals and doing something more practical...I would definitely attend this kind of training. (Health and Welfare, Turkey)

"In the future, when we conduct this workshop we have to focus on practical from start until the end... and also experience, real experience of how to deal with children in trauma. (Education and Health, Indonesia) 
While overall participants positively appraised the training provided, the overwhelming message from them was that they would welcome further practical ideas on how to manage the children they worked with or cared for "need to make it practical" (Health and Welfare, Turkey). This is an important lesson for those providing training to heed, as there are many practical strategies from the evidence-base that can be applied with children in trauma. However, such delivery needs to account for different levels of experience and skills amongst the delegates:

I think workshops can be split up into two groups: one group consisting of volunteers who have no psychological background and one group includes psychologists... (Welfare and Health, Turkey)

"...we are requesting...to offer some advanced courses that we could offer to our senior students. (Health, Pakistan)

Participants recognized that their groups had different levels of experience of working with children in trauma, thus some required more "advanced courses" (Health, Pakistan). It was not clear though whether this may have also reflected some reluctance or anxiety in interprofessional working (“one group includes psychologists”- Welfare and Health, Turkey). In so doing, it was also stated that to have this training provision there was a need for policy and financial support, which is limited in those countries:

I think it needs support from all the stakeholder, from the care home, from the government, from the staff and all the staff that give care to the children. (Welfare, Indonesia)

...yeah, of course we need to find support. Not only financial support from government and from our university, and we also need to build...the services must be...not so expensive. (Education and Health, Indonesia)

We need any support, either financial, more trainings. There is no way this can be sustained. (Welfare, Kenya) 
Participants recognized the relevance and importance of gaining support from governments, organizations and charities to ensure the longevity of key messages, but did feel that more training was needed. Furthermore, they reported that a holistic approach was needed from “care home, government, staff” (Welfare, Indonesia), and so forth. In other words, ongoing interprofessional collaboration and communication were considered essential in sustaining the skills and impact on practice on the ground:

We can join to build on workshop in the future, and we organize by sharing the interest. I have little experience of traumatized children, so I hope we can join to increase that. (Health, Indonesia)

We wish to keep on building our partnership, and make it stronger and more visible, and also have planned activities... and if we could have a joint action plan for, let's say, five years or three years. (Welfare, Rwanda)

Notably, this collaboration and spirit of sharing was felt to extend beyond single professional groups, and participants argued that a child-centred approach was essential in cutting across all agencies. They added that future training should also include the children themselves and their parents/caregivers to incorporate user perspectives:

Including children to the trainings would be beneficial. But I do not know how, to be honest. (Education and Health, Turkey)

...in terms of what we in the visits are obviously training, but like I said, perhaps individual meetings with parents or even group meeting with parents. (Welfare, Pakistan)

\section{Discussion}

This study draws on several timely as well as challenging issues, on the role of interprofessional training in enhancing vulnerable children's wellbeing in six LMIC, in the absence of specialist services. The severe and recurrent adversities experienced by children, families and communities in LMIC often result in high rates of inter-related and largely unmet children's mental and physical health, educational and social care needs (Hussein et 
al., 2012). The findings highlight stakeholders' impressions of an evolving programme, conceptualization of children's and practitioners' needs, identification of cultural and resources barriers, and their vision on how they could be supported in sustaining impact in the future. Key findings demonstrate their appreciation of sharing knowledge and experiences across professional groups; developing practice-based knowledge, awareness to challenge stigmatizing attitudes, and an international perspective; improved communication and relationships with children; and feeling empowered in their role. As such in terms of resilience-building, within the context of the resilience-buffering hypothesis, in which these factors, or consideration of these factors, are important across professions. It is important to acknowledge that none of the core themes focused on interprofessional learning per se, which indicates its early stage in LMIC settings.

In high-income countries, interprofessional collaboration is considered desirable in child mental health care delivery (Vostanis et al., 2015). Despite the challenges that are inherent in inter-agency communication, collaboration and partnership between disciplines promotes a holistic view of the child's difficulties (O'Reilly et al., 2013). Although in countries like the UK interprofessional working is common and to some extent expected (Anderson, Hean, O'Harloran, Pitt, \& Hammick, 2014), in LMIC training in mental health clearly needs to promote and create opportunities for key stakeholders to communicate with each other.

In relation to the interprofessional context, participants appeared to welcome sharing experiences and case material, and understanding different perspectives. These views reflect an indirect endorsement of interprofessional care principles, which were relatively novel to these stakeholders, despite the seniority and experience of many of those. There was no overt evidence from these findings of connection between the training and interprofessional care 
implications such as establishing networks and joint care pathways. This was possibly also related to the foundation training primarily focusing on trauma and its impact, with sharing of participants' experiences, rather than proposing a model drawing on participants' (and indeed service users') expertise on needs-led and innovative implementation. Adopting such a needsled model (e.g. described in Eruyar et al., 2017) in conjunction with an interprofessional framework from the outset may have led to themes being centred on interprofessional learning.

These future stages will require supporting policy, and collaboration between central and local government departments with operating NGOs. Evidence on the contribution of interprofessional training and services in maximizing resources and efficiency would be particularly appealing to international bodies and LMIC governments. Policy standards, preferably accompanied by funding streams that expect interprofessional collaboration for the benefit of children and communities, are more likely to be effective. Joined up policy, service planning and ongoing training should be driven by these principles, and should be regularly monitored by national and local networks. Indeed, analysis of the need for greater political alignment between interprofessional learning and collaborative practice was an overriding theme of the recent analysis on impact for propelling service delivery and patient care by the US Institute of Medicine (IOM, 2015).

Regarding the content, format and learning style of the workshops, participants appreciated the combination of providing a theoretical framework with skill acquisition on children's development, impact of trauma and resilience-building strategies; and, crucially, relating both these aspects to their roles and agencies. This is a challenge for interprofessional education for practitioners working with vulnerable groups who experience multiple and inter- 
connected needs in high-income countries (Vostanis, 2016a). Cultural adaptation of all these training components is clearly important (Pecukonis, Doyle, \& Bliss, 2008), although it was encouraging to detect similar views across different cultures and societies.

It is well-established that raising mental health awareness has a positive effect, not only in reducing stigma, but also in promoting positive outcomes for children diagnosed with mental health problems (Pinfold et al., 2003). In LMIC, stigma is known to be pronounced in relation to different types of vulnerability such as AIDS and disability, which in turn are strongly associated with disadvantage (Cluver, \& Orkin, 2009). Such a training forum can thus enable professionals to challenge their own attitudes and beliefs before tackling stigma in their communities.

Awareness of the complexities of mental health problems is especially important in designing and implementing interventions for vulnerable groups living in disadvantage (Vostanis, 2016b). In doing so, participants begin to understand why this can preferably be achieved through interprofessional working and community engagement, even more so in the absence of specialist resources (Raikes, Yoshikawa, Britto, \& Iruka, 2017). Adopting an ecological systems framework of viewing the child within their micro, meso, exo and macro system (Bronfenbrenner, 1979) reinforces an interprofessional stance in concurrently intervening at multiple levels. Foundation training should be an initial step in this process, from education and promotion of child mental wellbeing to acquisition of new core skills tailored to current knowledge and skill level (Oandasan, \& Reeves, 2005; O’Reilly, Dogra, Williams, Edwards, \& Vostanis, 2010). An important workforce strategy in developing sustainable services is to ensure that knowledge is translated and delivered through local trainers. In addition to the reported language and conceptual barriers during the training, sustainability cannot be 
dependent on the original training providers from western countries, because of the resource issues involved and the need to adapt to each sociocultural context.

There are several resource implications to also consider from the findings. A major challenge is the recognition and embedment of training within one's professional role. Such issues are not uncommon in any country, for examples teachers in high-income countries, who can often only attend training before the beginning of the school-term, after school ('twilight zone') or through costly replacement by teaching assistants (Vostanis, Humphrey, Fitzgerald, Deighton, \& Wolpert, 2013). Joint planning of training and service provision could use resources to their maximum effect without duplication, for example through joint training on core practice-based skills, and separate training on child protection or specific mental health topics. Community engagement, training of volunteers and user input would also contribute to the efficient use of spare specialist resources (Patel et al., 2011). Taking advantage of new technologies such as e-learn courses can make knowledge more accessible and sustainable (Rahman et al., 2006). Foundation training, as provided by the programme under evaluation, could be complemented by targeted courses on specific competencies in therapeutic modalities like attachment- or trauma-focused interventions (Allen, \& Vostanis, 2005).

The evaluation of the findings needs to take into consideration a number of methodological limitations such as the selection of the sample among training participants, who could thus have been more positively predisposed to mental health issues and more motivated to train in an interprofessional context. Their perceptions of how the training may have influenced their practice were not corroborated by service data and user outcomes, preferably over a longer period. Participants were not members of an interprofessional team, although this was inherent to the service gaps that guided the research questions. No service users, i.e. children, 
young people and parents were included in this study. It would have been useful to have interviewed participants before the training events, and to have complemented the data with pre-post training questionnaire ratings on knowledge, skills and attitudes (Vostanis et al., 2011). Language and conceptual barriers during the training, which were compounded by the use of interpreters, were additional limitations. The six countries involved have different policies, health and welfare systems, and cultural norms. Yet, this was a unique sample, and the findings indicate more similarities rather than differences in the emerging themes.

\section{Concluding comments}

This international training programme in LMIC countries and the emerging findings indicate that learning and working in an interprofessional context is broadly welcome by participants, although this was a new concept of initially collaborative rather than interprofessional practice. A number of benefits and early perceived impact were identified, as well challenges and recommendations on how to overcome them. Solutions relate to inter-linked policy, resource, staff competencies and practice implementation. Future research should establish in more depth how the reported barriers could be overcome to move from isolated practice to collaboration and ultimately to interprofessional teamwork, defined as different health and social care professions who share an identify and work together to deliver services, in such adverse LMIC settings for vulnerable children and young people (Reeves et al., 2010).

\section{Declaration of interest}

The authors report no conflicts of interests. The authors are responsible for the writing and content of this article. We are grateful to all participants for their input to the training and the interviews. This study was supported by the Research Impact Development Fund through the University of Leicester. 


\section{References}

Abera, M., Robbins, J., \& Tesfaye, M. (2015). Parents' perception of child and adolescent mental health problems and their choice of treatment option in southwest Ethiopia. Child and Adolescent Psychiatry and Mental Health, 9, 40, DOI: 10.1186/s13034-015-0072-5

Allen J., \& Vostanis P. (2005). The impact of abuse and trauma on the developing child: An evaluation of a training programme for foster carers and supervising social workers. Adoption and Fostering, 29, 68-81.

Amuyunzu-Nyamongo, M., (2013). The social and cultural aspects of mental health in African societies. Commonwealth Health Partnerships, 59-63.

Anderson, E.S., Hean, S., O’Halloran, C., Pitt, R., \& Hammick, M. (2014). Faculty development and interprofessional education and practice. In: Y. Steinert (Ed.), Faculty Development in the Health Professions: A focus on Research and Practice (pp. 287-310). New York: Springer.

Bernard, H.R (2000). Social Research Methods: Qualitative and Quantitative Approaches. Thousand Oaks, CA: Sage.

Braun, V., \& Clarke, V. (2006). Using thematic analysis in psychology. Qualitative Research in Psychology, 3, 77-101

Boyatzis, R. (1998). Transforming Qualitative Information: Thematic Analysis and Code Development. London: SAGE.

Bronfenbrenner, U. (1979). The Ecology of Human Development: Experiments by Nature and Design. Cambridge, MA: Harvard University Press.

Burr, V. (2003). Social Constructionism, second edition. London: Routledge.

Charles, A. (2017). Developing Accountable Care Systems: Lessons from Canterbury New Zealand. London: The Kings Fund.

Cooper, M., Evans, Y., \& Pubis, J. (2016). Interagency collaboration in children and young people's mental health: A systematic review of outcomes, facilitating factors and inhibiting factors. Child: Care, Health and Development, 42, 325-342.

Cluver, L., \& Orkin, M. (2009). Cumulative risk and AIDS-orphanhood: Interactions of stigma, bullying and poverty on child mental health in South Africa. Social Science and Medicine, 69, 1186-1193.

Draper, A.K., Hewitt, G., \& Rifkin, S. (2010). Chasing the dragon: Developing indicators for the assessment of community participation in health programmes. Social Science and Medicine, 71, 1102-1109.

Eruyar, S., Huemer, J., \& Vostanis, P. (2017). How should child mental health services respond to the refugee crisis? Child and Adolescent Mental Health, doi:10.1111/camh.12252

Fazel, M., Patel, V., Thomas, S., \& Tol, W. (2014). School mental health interventions in low-income and middle-income countries. The Lancet Psychiatry, 1, 388-398. 
Fleitlich-Bilyk, B., \& Goodman, R. (2004). Prevalence of child and adolescent psychiatric disorders in Southeast Brazil. Journal of the American Academy of Child Adolescent Psychiatry, 43, 727-734.

Gilbert, J. (2005). Interprofessional learning and higher educational structural barriers. Journal of Interprofessional Care, Supplement 1, 87-106.

Green, H., McGinnity, A., Meltzer, H. Ford, T., \& Goodman, R. (2005) Mental Health of Children and Young People in Great Britain. London: HMSO.

He, A., Lim, C., Lecklinter, G., Olson, A., \& Traube, D. (2015). Interagency collaboration and identifying mental health needs in child welfare: Findings from Los Angeles County. Children and Youth Services Review, 53, 39-43.

Hussein, S., Vostanis, P., Bankart, J. (2012). Social and educational risk factors for child mental health problems in Karachi, Pakistan. International Journal of Mental Health and Culture, 5, 1-14.

Hussein, S., \& Vostanis, P. (2013). Teacher training intervention for early identification of common child mental health problems in Pakistan. Emotional and Behavioural Difficulties, 18, 284-296.

IOM - Institute of Medicine (2015). Measuring the Impact of Interprofessional Education on Collaborative Practice and Patient Outcomes. Washington, DC: National Academies Press.

Johnson, J., Wood, A., Gooding, P., Taylor, P., \& Tarrier, N. (2011). Resilience to suicidality: The buffering hypothesis. Clinical Psychology Review, 31, 563-591.

Kieling, C., Baker-Henningham, H., Belfer, M., Conti, G., Ertem, I., Omigbodun, O., Agusto Rohde, L., Srinath, S., Ulkuer, N., \& Rahman, A. (2011). Child and adolescent mental health worldwide. Lancet, 378, 1515-1525.

Knerr, W., Gardner, F., \& Cluver, L. (2013). Improving positive parenting skills and reducing harsh and abusive parenting in low- and middle-income countries: A systematic review.

Prevention Science, 14, 352-363.

Losa, N., \& Effat, R. (2017). Service users and carers in low- and middle-income countries. British Journal of Psychiatry International, 14, 4-6.

Lund, C., Tomlinson, M., \& Patel, V. (2016). Integrating mental health into primary care in low- and middle-income countries. British Journal of Psychiatry, 208 (s56) s1-s3; DOI: 10.1192/bjp.bp.114.153668

Madge, N., Foreman, D., \& Baksh, F. (2008). Starving in the midst of plenty: A study of training needs for child and adolescent mental health service care delivery in primary care. Clinical Child Psychology and Psychiatry, 13, 473-478.

Maltby, J., Day, L., \& Hall, S. (2015). Refining trait resilience: Identifying Engineering, Ecological, and Adaptive facets from extant measures of resilience. PloS One, 10(7), e0131826. https://doi.org/10.1371/journal.pone.0131826 
NHS England (2014). Model Specification for Child and Adolescent Mental Health Services: Targeted and Specialist Levels (Tiers 2/3). London: Department of Health.

NHS England (2015). Future in Mind: Promoting, Protecting and Improving our Children's and Young People's Mental Health and Wellbeing. London: Department of Health.

Oandasan, I., \& Reeves, S. (2005). Key elements for interprofessional education. Part 1: The learner, the educator and the learning context. Journal of Interprofessional Care, 19, 21-38.

O’Reilly, M., Dogra, N., Williams, R., Edwards., R., \& Vostanis, P. (2010). Turning policy into practice: An evaluation of policy for and delivery of education and training for specialist CAMHS staff in England. Evidence and Policy, 6, 505-526.

O'Reilly, M., \& Parker, N. (2013). 'Unsatisfactory saturation': A critical exploration of the notion of saturated sample sizes in qualitative research. Qualitative Research, 13, 190-197.

O'Reilly, M., Taylor, H., \& Vostanis, P. (2009) "Nuts, schiz, psycho": An exploration of young homeless people's perceptions and dilemmas of defining mental health. Social Science and Medicine, 68, 1737-1744.

O’Reilly, M., Vostanis, P., Taylor, H., Day, C., Street, C., \& Wolpert, M. (2013). Service user perspectives of multi-agency working: A qualitative study with children with educational and mental health difficulties and their parents. Child and Adolescent Mental Health, 18, 202-209.

OECD - Organization for Economic Co-operation and Development (2016). Country Risk Classification. Retrieved from http://www.oecd.org/tad/xcred/crc.htm

Pangallo, A., Zibarras, L., \& Lewis, R. (2015). Resilience through the lens of interactionism: A systematic review. Psychological Assessment, 27, 1-20.

Patel, V., Chowdhary, N., Rahman, A., \& Vardeli, H., (2011). Improving access to psychological treatments: Lessons from developing countries. Behaviour Research and Therapy, 9, 523-528.

Patel, V., \& Rahman, A. (2015). An agenda for child mental health. Child and Adolescent Mental Health, 20, 3-4.

Pecukonis, E., Doyle, O., \& Bliss, D.L. (2008). Reducing barriers to interprofessional training: Promoting interprofessional culture competence. Journal of Interprofessional Care, $22,417-428$.

Pinfold, V., Toulmin, H., Thornicroft, G., Huxley, P., Farmer, P., \& Graham, T. (2003). Reducing psychiatric stigma and discrimination: Evaluation of educational interventions in UK secondary schools. British Journal of Psychiatry, 182, 342-346.

Rahman, A., Nizami, A., Minhas, A., Niazi, R., Slatch, M., \& Minhas, F. (2006). E-mental health in Pakistan: A pilot study of training and supervision in child psychiatry using the internet. Psychiatric Bulletin, 30, 149-152. 
Raikes, A., Yoshikawa, H., Britto, P.R., \& Iruka, I (2017). Children, Youth and Developmental Science in the 2015-2030 Global Sustainable Development Goals. Society for Research in Child Development, Social Policy Report 30, 3.

Reeves, S., Lewin, S., Espin, S., \& Zwarenstein, M. (2010). Interprofessional Teamwork for Health and Social Care. Oxford: CAIPE-Wiley Blackwell.

Roulston, K. (2010). Reflective Interviewing: A Guide to Theory and Practice. London: SAGE.

Rutter, M. (2013). Resilience: Clinical implications. Journal of Child Psychology and Psychiatry, 54, 474-87.

Ryan, G., \& Bernard, H. (2003). Techniques to identify themes. Field Methods, 15, 85-109.

Sebuliba, D., \& Vostanis, P. (2001). Child and adolescent mental health training for primary care staff. Clinical Child Psychology and Psychiatry, 6, 191-204.

Vostanis P. (2010). Mental health services for children in public care, and other vulnerable groups: implications for international collaboration. Clinical Child Psychology and Psychiatry, $15,555-571$.

Vostanis, P. (2016a). A Practical Guide to Helping Children and Young People who Experience Trauma. London: Speechmark.

Vostanis, P. (2016b). New approaches to interventions for refugee children. World Psychiatry, $15,75-77$.

Vostanis, P., Humphrey, N., Fitzgerald, N., Deighton, J., \& Wolpert, M. (2013). How do schools promote emotional well-being among their pupils? Findings from a national survey of mental health provision in English schools. Child and Adolescent Mental Health, 18, 151157.

Vostanis, P., Martin, P., Davies, R., De Francesco, D., Jones, M., Sweeting, R., Ritchie, B., Allen, P. \&, Wolpert, M. (2015). Development of a framework for prospective payment for child mental health services. Journal of Health Services Research and Policy, 20, 202-209.

Vostanis P., Meltzer H., Goodman R., \& Ford T. (2003). Service utilisation by children with conduct disorders: Findings from the GB national study. European Child and Adolescent Psychiatry, 12, 231-238.

Vostanis, P., Taylor, H., Day, C., Edwards, R., Street, C., Weare, K., \& Wolpert, M. (2011). Child mental health practitioners' knowledge and experiences of children's educational needs and services. Clinical Child Psychology and Psychiatry, 16, 385-405.

Windle, G., Bennett, K., \& Noyes, J. (2011). A methodological review of resilience measurement scales. Health and Quality of Life Outcomes, 9, 8 https://doi.org/10.1186/14777525-9-8

WHO - World Health Organization (2010). Framework for Action on Interprofessional Education and Collaborative Practice. Geneva: WHO. 
Worrall-Davies, A., \& Cottrell, D. (2009). Outcome research and interagency work with children. Children and Society, 23, 336-346.

Yin, R. (2012). Applications of Case Study Research. London: Sage. 